\title{
Weather contributes to record ozone loss
}

London. A combination of satellite, balloon and ground-based data have confirmed that this year's Antarctic ozone 'hole' is the deepest ever recorded. But weather conditions may have been as much to blame as the build-up of atmospheric chlorofluorocarbons (CFCs).

On 6 October, a balloon launched from the South Pole by the Climate Monitoring and Diagnostic Laboratory (CMDL) of the US National Oceanic and Atmospheric Administration found total ozone concentration of only 90 Dobson units (DU). This compares to pre-depletion values of 275 DU, and to last year's minimum of $105 \mathrm{DU}$.

On the same day, a surface-based Dobson spectrophotometer recorded an ozone concentration of only $88 \mathrm{DU}$. These measurements represent the lowest value of total column ozone ever measured on Earth. (A Dobson unit is a measure of the thickness of the ozone layer if it was brought to the Earth's surface.)

Preliminary data from the National Aeronautics and Space Administration (NASA)'s total ozone mapping spectrometer (TOMS) instrument aboard the Russian Meteor-3 satellite also show October ozone values of less than $100 \mathrm{DU}$ in a region near the South Pole. And at Halley Station, scientists from the British Antarctic Survey observed a minimum daily mean ozone value of 100 DU during October, compared to 107 DU last year.

The depth of this year's hole has come as a surprise to most atmospheric scientists. Chlorine released in the stratosphere from man-made chemicals such as CFCs is believed to be the main cause of stratospheric ozone depletion, and there is certainly more in the atmosphere this year than last.

But this should not necessarily have led to a deeper hole, as chlorine is released into its active form primarily in the presence of heterogeneous surfaces on which key chemical reactions can take place. These surfaces can be provided by polar stratospheric clouds (PSCs), which form only under extremely cold conditions, or by aerosol particles which occur over a restricted height range.

Last year's destruction in Antarctica seemed to account for virtually all of the ozone present at the limited altitudes over which such surfaces can occur. As a result, most scientists expected the ozone depletion to have reached its maximum this year, in spite of the extra chlorine present.

David Hofmann, from the CMDL, believes that the vertical resolution of the balloon-borne instruments may answer the question of why this year's ozone concentration is so low. During soundings over the South Pole on 6 and 12 October, the balloons recorded complete ozone destruction from about 13.5 to $19 \mathrm{~km}$. But the data also show that most of this year's additional

depletion took place higher in the stratosphere than last year, from 18 to $23 \mathrm{~km}$.

According to Hofmann, the balloons also detected record low temperatures in the Antarctic stratosphere. This means that PSCs may have formed at higher altitudes than is usually possible. Rich McPeters of NASA's Goddard Space Flight Center in Maryland says that this year's Antarctic vortex seems to have been very stable, which could have allowed unusually cold conditions to develop.

As a result, the unprecedented depth and vertical extent of this year's hole may owe more to meteorological conditions than to extra anthropogenic emissions of CFCs and other chlorine-containing species.

But both effects are likely to have played a role. Indeed the cold temperatures themselves may not be entirely free from anthropogenic influence. Hofmann points out that ozone acts as a stratospheric heater; ozone depletion can therefore lead to lower

\section{National supercomputer centre urged for US}

Washington. The United States should set up a national, multi-agency supercomputer facility in order to push back the limits of high-performance computing, according to a panel of experts set up by the National Science Foundation (NSF).

Lewis Branscomb, formerly Research Director at IBM, now at Harvard University's Kennedy School of Government, says that such a facility would sit at the apex of a "high-performance computing pyramid" serving all the nation's research needs. He estimates that it would cost about $\$ 50$ million a year to set up and run.

Several members of the NSF panel dissented from the proposal to set up a national centre, arguing that it would be both ineffective and expensive. But Branscomb, a physicist who headed the National Bureau of Standards under President Jimmy Carter, argues strongly for "one national facility that would stretch the [supercomputer] industry".

Establishing a supercomputer pyramid would allow four existing supercomputer centres to be retained, alleviating fears that some or all of them might be closed. And the panel also additionally recommends that NSF should help every research university in the United States to buy its own mid-sized supercomputer, using the new 'massively parallel' architectures, over the next five years. Support for scientists and engineers buying their own workstations should be doubled, it says.

According to Branscomb, the panel is confident that the additional funding required to fulfil its recommendations will become available under the federal High Performance Computing programme. This was launched under former President George Bush, and remains strongly supported by the Clinton administration.

The report says that a new central facility would provide "significant stimulus to commercial development" of future supercomputers delivering teraflop performance, that is, that measured in a million million floating point operations per second. It suggests that the centre should be run jointly by NSF and other federal agencies.

Although urging that the four existing centres should be retained, the report also calls on them to exercise more flexibility and to work more closely with other institutions. "The centres should no longer be seen just as places where gigabytes are farmed out to scientists," Branscomb says.

The NSF, whose new director Neal Lane was sworn in last week by President Bill Clinton, will prepare a plan for implementing the panel's recommendations for submission to the foundation's governing board early next year.

Colin Macilwain 